\title{
Study on Correlation of Foreign Language Anxiety and English Reading Anxiety
}

\author{
Qian Huang \\ Foreign Language Teaching Department, Dezhou University, Dezhou 253023, China \\ Email: qqh@dzu.edu.cn
}

\begin{abstract}
This paper firstly gives the definition of anxiety and its classification and then states the sources of foreign language anxiety. Research has made on the correlation between foreign language anxiety and reading anxiety, which shows Chinese students are bothered by reading anxiety coming from their lack of background knowledge and psychological factors such as anxiety, fear, bad reading habit and low interest in foreign language, etc. According to the above discussion, the paper gives the four strategies to help the students overcome reading anxiety, promoting students reading efficiency and we English teacher also can get teaching implication on this issue.
\end{abstract}

Index Terms - foreign language anxiety, English reading anxiety, correlation

\section{DEFINITION OF ANXIETY AND ITS CLASSIFICATION}

\section{A. Definition of Anxiety}

Due to different purposes of different researches, anxiety may have different definitions. From psychological point of view, anxiety is defined as "a state of apprehension, a vague fear that is only indirectly associated with an object" by Psychologists like Higard, Atkinson. (Scovel, 1978). From the perspective of the behavior science, B.B. Wolman (1989) denotes anxiety as "a feeling of one's own weakness and inability to cope with real or imaginary threats. In recent years, it is widely recognized and accepted by language researchers that anxiety has close relationship with foreign language learning. Therefore it is frequently and extensively employed to perform foreign language research. Spielberger (1983) defines anxiety as "the subjective feeling of tension, apprehension, nervousness, and worry associated with an arousal of the automatic nervous system".

\section{B. Types of Anxiety}

From the psychological perspective, anxiety is often classified into three types, that is"trait, state and situation-specific anxiety" (MacIntyre \& Gardner,1989). Trait anxiety is a stable predisposition; people with high levels of trait anxiety are generally nervous people in a wide range of circumstances. State anxiety is "an apprehension expected at a particular moment in time as a response to a definite situation." (Spielberger, 1983). The third type of anxiety is situation-specific anxiety. Situation-specific anxiety "can be seen as trait anxiety limited to a given context" (MacIntyre \& Gardner, 1991). It may be stable over time but inconsistent with various situations. That is, this type of anxiety is intrigued by a specific situation or event over time, such as taking a test, public speaking, class participation, talking with a foreigner in a foreign language, solving physical problem. Because of the features of situation-specific anxiety, MacIntyre and Gardner (1991) suggest that "foreign language anxiety should be studied with situation specific measures". According to Horwitz et al. (1986) foreign language classroom anxiety is a typical situation-specific anxiety.

\section{SOURCE OF Foreign LANGUAGE ANXIETy}

In order to reduce or avoid the negative influence of foreign language anxiety, it is helpful for us to explore the sources of foreign language anxiety, which can help us better explain the effects of anxiety on foreign language learning and also help English teachers find practical and effective teaching programs and strategies. Having reviewed the literature on language anxiety (Bailey, 1983) Horwitz et al., 1986; Young, 1991) many potential sources have been found. Here several main sources of foreign language anxiety from highly personal (such as competitiveness) to procedural (such as language examination).

\section{A. Personal Factors}

\section{Self-esteem}

Self-esteem is a "self-judgment of worth or value, based on feelings of efficacy, a sense of interacting effectively with one's own environment" (Oxford, 1990). Krashen(1983) states that foreign language anxiety is easily evoked by an individual's self-esteem. What other people think may cause the individuals with low self-esteem worried, because they want to please others.

2. Competitiveness 
When people learn to use a foreign language to communicate, it is natural for them to compare themselves with others or with their idealized self-image which may be hard to realize. Thus competitiveness arouses, which can also lead to language anxiety (Bailey, 1983). However, competitiveness may not arouse anxiety in all students.

3. Beliefs

Language anxiety can be the result of some unscientific or impractical beliefs of both learners and their teachers (Oxford, 1993). Sometimes when the learners' expectation or beliefs on foreign language learning are unrealistic, frustration and stress are inevitable and accordingly anxiety appears. Some teachers in foreign language class tend to criticize every mistake that learners have made or frequently correct the student's poor pronunciation, which will easily intrigue learners' anxiety. As for a lot of language teachers, the role played by teachers in language class should be dominative, directive and authoritative; otherwise the class will be out of control. So when pair work or group work is conducted, they will have much worry about the order of classroom. Such a teacher-centered language class, in which learners just play a part as passive receivers of knowledge will easily made learners feel anxious in foreign language learning.

\section{B. Procedural Factors}

Language anxiety may be rooted in some highly procedural factors, such as classroom procedures, instructor-learner interactions and test anxiety. Not only oral tasks, but also writing, reading or listening can also create fear (Horwitz \&Young, 1991; Scarcella \& Oxford, 1992). Anxiety may be a result of some ineffective pedagogical practices. For example, in reading exercises, the teacher only check the answers or simply explain the meaning of each sentence or word, while reading strategies and the structure of the reading material are ignored. (Young, 1999) The instructor-learner interactions are also anxiety-provoking in language class. The nervousness of language learners can be easily stimulated by the teachers' harsh and uncomfortable error correction in front of a class.

\section{Culture Background}

From a social-cultural point of view, language acquisition will not perform successfully without the introduction of cultural of the target language. In the process of foreign language learning it is natural for the learner to encounter a large amount of culture shock. The culture shock may easily cause them to feel anxious because they are afraid of losing their own language and ethnic identity in cross-cultural circumstances. (Clement1980). Horwitz (2001) warned that it is significant to be aware of cultural differences when teachers are designing classroom practices or preparing lessons. Related culture knowledge is useful and helpful especially to students' reading in target language. Some practices prove to be relaxing and interesting to one group of learners may be difficult and boring for another group of learners from a different cultural because people from different culture background are used to different types of classroom organizations. So cultural differences may also lead to stress and anxiety. The studies on sources of foreign language anxiety are of great significance in that it not only contribute a better explanation of the relationship between foreign language anxiety and language achievement, but also help the foreign language teachers to work out more effective strategies and programs that may ameliorate the negative effects of language anxiety.

\section{ForEIGN LANGUAGE READING ANXIETY}

\section{A. Reading Is a Cognitive Process}

Reading plays a significant role in language learning. Anderson (1999) states reading is an essential skill for students to have a good command of a second or foreign language. For English learners, greater progress and development will be made in all academic areas, supposing their reading skills can be advanced. Wedell's defines reading as "a psycholinguistic process. Readers start with a set of linguistic symbols that have been chosen by writers to represent the thoughts that they wish to express. The reading process ends when the readers have interpreted as much of the writers' intended meaning as is relevant to them. So the writers put their meaning into language and the readers reconvert the language into meanings." (Wedell, 1995) His definition is one of the most frequently cited and widely accepted among numerous definitions of reading. Reading, is a cognitive activity. The three main elements involved in reading process are reader, text and interaction between the reader and the text. Chastain (1988) states that reading process is a cognitive system in which readers actively operate the printed materials to obtain a good comprehension of the text. In another word, during reading process the reader should make use of their background and linguistic knowledge to reconstruct the writer's intended meaning. In a word, the writer's intended meaning is under the printed materials and the reader should read between the lines to get it.

\section{B. Krashen's Affective Filter Hypothesis}

Comfortable reading needs to be unafraid. However, very often when one is studying something difficult or something that is difficult in one's own opinion, and when one is going to be tested, one's reading will not work well. These feelings make one feel difficult to concentrate, to remember the ideas, and to learn anything new. If one is reading for fun, usually one will not have the feeling of worry and nerve and anxiety. Stephen D. Krashen(1992) says that if the language acquirer is anxious or has low self-esteem it will be difficult to easily learn the foreign language. Acquirers with favorable and desirable attitudes are hypothesized to have "low" affective filters, adversely, to have 
"high" affective filters.

Affective Filter Hypothesis is first proposed by Dulay and Burt(1977), and latter is incorporated by Krashen as one of his five Hypotheses. According to the Affective Filter Hypothesis, affective factors as anxiety, self-doubt etc. are like a filter which filters language input out learners brains to make the amount of language input increase or decrease. People with high affective filter will decrease their input whereas people with low affective filter will increase their intake. Those negative emotions are regarded as a "mental block" that prevents efficient processing of the language input. The affective filter functions as a blockage to language acquisition, the filter varies to emotions of acquirers, when they lack confidence the filter is up, when they are not anxious the filter is down. The hypothesis states that the barrier can be reduced by encouraging interest, creating relaxed and low anxiety atmosphere, which implies that our pedagogical aims should not only include offering comprehensible input, what is important is to provide an encouraging environment of a low filter.

\section{InVESTIGATION AND Discussion On LANGUAGE ANXIETY AND ENGLISH READING ANXIETY}

Before the investigation of the states of English language anxiety and English reading anxiety experienced by non-English major students in EFL context, it is necessary and important to examine the reliability of FLCAS and FLRAS. These two scales have been extensively tested and widely used to investigate foreign language learning and reading anxiety. To assess the quality of adapted FLRAS and FLCAS, reliability and validity analysis were conducted in the present study. Cronbach's coefficient alpha for adapted FLCAS is.89 $(n=160)$, for adapted FLRAS is $.84(n=160)$. Therefore, compared with Saito et al.'s study (1999), Cronbach's coefficient alpha for FLCAS is. 93 and for FLRAS is $.86(n=383)$, the Chinese versions of the adapted FLCAS and FLRAS are satisfactorily reliable instruments to measure the levels of students' English language anxiety and English reading anxiety.

\section{A. The Relationship between FLCAS and FLRAS}

The relationship between English language anxiety and English reading anxiety was examined by conducting a Pearson production-moment correlation analysis.

TABLE1

CORRELATION BETWEEN FLCAS AND FLRAS

\begin{tabular}{|l|l|l|l|}
\hline \multicolumn{2}{|c|}{ CORRELATION BETWEEN FLCAS AND FLRAS } \\
\hline FLRAS & Pearson Correlation & FLRAS & FLCAS \\
& Sig. (2-tailed) & 1 & $.652^{* *}$ \\
& $\mathrm{~N}$ & 160 & .000 \\
& & 160 \\
\hline FLCAS & Pearson Correlation & $.652^{* *}$ & 1 \\
& Sig.(2-tailed) & .000 & 160 \\
& $\mathrm{~N}$ & 160 & 1601 level \\
\hline
\end{tabular}

From the above analysis, necessary measures should be taken to help the students overcome the anxiety in their English reading.

\section{B. Foreign Language Reading Anxiety Categories}

After the FLRAS was administered and scored, the 121 students were divided into three groups according to the results. Those whose scores are below 50 are considered as LOW-ANX, accounting for $14 \%$ of the total, while those who score higher than 68 (including 68) are classified into the HI-ANX, taking up 18\% of the total. The rest who gain scores between 50and 66 are considered as AVE-ANX, covering 68\%. Thus there are 17 and 22 students in LOW-ANX group and HI-ANX group respectively and 82 in AVE-ANX group. Figure presents the number and percentage of students in each Table1 FLRA category and the anxiety level and range for each identified group.

\begin{tabular}{|l|l|l|l|l|}
\hline $\begin{array}{l}\text { FLRA } \\
\text { CLASSIFICATION }\end{array}$ & Number & Percentage & Mean & Range \\
\hline LOW-ABX & 17 & $14 \%$ & 44.471 & $30 \%$ to 49 \\
\hline AVE-ANX & 82 & $68 \%$ & 59.444 & 50 to 69 \\
\hline HI-ANX & 22 & $18 \%$ & 73.565 & 68 TO 99 \\
\hline
\end{tabular}

\section{Anxiety and Reading Comprehension Score}

In order to examine the influences of different levels of anxiety on the reading performance, the correlation coefficients between the three levels of anxiety (low-anxiety, average-anxiety and high-anxiety) and the corresponding reading comprehension scores were calculated. The three anxiety groups are classified according to the cumulative percent of anxiety of the 121 subjects. Table 3 presents the descriptive statistics for the three anxiety groups and the corresponding reading comprehension scores. 
TABLE 3

DESCRIPTIVE STATISTICS OF THE THREE ANXIETY GROUPS AND THE CORRESPONDING READING COMPREHENSION SCORES

\begin{tabular}{|c|c|c|c|c|c|}
\hline & $\mathrm{N}$ & Minimum & Maximum & Mean & Std. \\
\hline FLRA LOW-ANX & 17 & 30.00 & 49.00 & 44.4706 & 5.52401 \\
\hline FLRA AVE-ANX & 82 & 50.00 & 99.00 & 59.9268 & 6.42868 \\
\hline FLRA & & & & & \\
\hline HI-ANX & 22 & 67.00 & 89.00 & 72.4091 & 5.34219 \\
\hline CETR LOW-ANX & 17 & 186.00 & 366.00 & 314.1176 & 56.43900 \\
\hline CETR AVE_ANX & 82 & 366.00 & 520.00 & 437.2439 & 44.43293 \\
\hline CETR & & & & & \\
\hline HI-ANX & 22 & 532.00 & 630.00 & 577.8636 & 33.52511 \\
\hline Valid N (listwise) & 0 & & & & \\
\hline
\end{tabular}

As shown in Figure 4.6, the data computerized in SPSS imply the fact that FLRA and reading comprehension score of CET-4 confirms that students who are of lower anxiety tend to have better achievement, while highly anxious students achieve less.

\section{Correlation between the Three Anxiety Levels and the Corresponding Reading Comprehension Scores}

Correlation coefficients between the three anxiety levels and the corresponding reading comprehension scores are presented in table 4.7. The results demonstrate that Correlation coefficients between the two variables are significant, a significant negative correlation exist among mid-anxiety group and high-anxiety group. Whereas low-anxiety has a positive but insignificant correlation with reading comprehension score.

TABLE 4.

PEARSON CORRELATION BETWEEN THE THREE ANXIETY LEVELS AND THE CORRESPONDING READING COMPREHENSION SCORES

\begin{tabular}{|l|l|}
\hline & Reading comprehension score \\
\hline LOW-ANX & .025 \\
\hline AVE-ANX & $-.191^{* *}$ \\
\hline HI-ANX & $-.235^{* *}$ \\
\hline & $* *$ Correlation is significant at the 0.01 level (2-tailed). \\
Note: LOW-ANX = Low Anxiety Group \\
AVE-ANX= Average Anxiety Group \\
HI-ANX=High Anxiety Group
\end{tabular}

As reported in Table 4. and the group analysis of reading comprehension scores above, it can be concluded that low anxiety has a positive but insignificant correlation with reading comprehension score, while a significant negative correlation exists among mid-anxiety group and high-anxiety group. This result further proves the negative influence of reading anxiety on reading performance, but also suggests that reading anxiety can facilitate reading comprehension at a certain point.

\section{StRATEGIES TO OVERCOME THE ANXIETY OF READING}

\section{A. To Help Students Strengthen Their Faith in English Reading}

Reading plays an important role in learning English, it provides readers with much information and rich language forms, which enriches one's comprehensive knowledge. For example, through reading, learners can enlarge their vocabulary, can learn to use some sentence structures, can acquire some cross-cultural information, can accumulate many useful expressions etc. however, most English learners regard that reading is less important than speaking, listening and writing, to learn English is to learn to speak and write in English, such awareness will seriously prevent them from improving reading ability, once students lose faith in reading, they will bring some negative factors to the process of reading.

According to investigation, majority of students believe that their reading anxiety results from new words and unfamiliar grammar, while vocabulary and grammar are surface levels in Structuring a passage and it is easy for students to overcome this difficulty by remembering and practicing. However, the faith in reading belongs to the problem of attitude. If students can't treat reading with proper attitude, it will lead directly to the sense that they are far away from the target language, that is anxiety of language distance. When they have no faith in reading, students will blindly choose some reading strategies, some students even have the tendency to give up. For those having no faith, they regard reading as a passive process, this concept makes them blindly deal with what they are reading, which further intensifies the distance from target language and the feeling of anxiety. So developing students' faith in reading during teaching is very important, by this way, students will be promoted to expose themselves to English reading materials, much reading will make them accumulate much more vocabulary and grammar, then they will read English with such familiarity that they will not feel nervous any more. In teaching reading, teachers should afford efficient and 
immediate instruction to develop students' faith in reading.

\section{B. To Help Students Develop Their Cross-cultural Competence}

For second language learners, cross-cultural competence is a must. Unfamiliar foreign history and culture will become a great barrier preventing learners from correctly understanding a text. When reading a text involving in foreign culture, those lacking cross-cultural knowledge will be confused and feel afraid of knowing nothing. It is a misunderstanding that reading is just a thing that you can do some questions of choice correctly, it is really not such a matter. Reading is a complex process, readers obtain information through words and sentences then rearrange what they have got and turn them into their own thoughts. This process is communication between writer and reader, so if reader lacks knowledge in some aspects, he will not understand what the writer wants to transmit by words, then the communication will be stopped. The best way to learn second language is to put learners into the foreign culture. When learners become familiar with foreign culture, they will feel English reading easier. Strange culture can trigger the higher level of reading anxiety, so in order to let students feel relaxed when meeting with foreign culture, we should pay attention to strengthen their cross-cultural awareness, it is strongly suggested that more lectures on foreign culture and diverse topics related to foreign culture be offered to broaden students' horizons. Both teachers and students should improve their sensitivity of cultural awareness.

\section{To Encourage Cooperative Learning}

Cooperative learning helps to mobilize enthusiasm of each student and makes them freely participate in learning activities. In cooperative way of learning, the whole class is divided into several small groups, each member of one group shoulders responsibility for his own and other members, because the reward of individual achievement is obtained by the efforts of group members, so based on this view, cooperative learning can encourage each student to try his best to behave and perform well. Cooperative learning enhances the interaction between student and student and helps to form a supportive atmosphere. Students get more opportunities to freely talk and share their thoughts with group-mates. When they try to finish one reading assignment together, one student will see how their peers develop by immediate communication, he will be not afraid that he may be the only one who meets with difficulty. By discussing in a group, each student is provided with a less anxiety-producing situation in which students have no tension to express. Cooperation makes students be aware that reading is not a matter of oneself but a matter of each group member, only by working together, communicating with each other, new ideas can be tried out, one's reading skills can be improved, tension and anxiety can be reduced.

\section{To Help Students Build Self-confidence}

To build self-confidence is very important in learning language and reading English. Self-confidence is a kind of active attitude, is a kind of healthy self-concept. It helps to change some negative factors into positive ones. It is easy to find that those having self-confidence are more likely to achieve success than those lacking self-confidence. Self-confidence functions greatly in making students keep the inner self-esteem, also functions when students are affected by all kinds of affective factors. Because reading is regarded as a complex psychological process, when reading, readers will experience different kinds of complex emotions, if one can keep confident, one may overcome those negative affective factors such as anxiety or confusion, if one lose confidence, one may suffer anger or anxiety even other kinds of emotional pains. In reading an article, when meeting with such and that difficult, if a student has no confidence, he will believe that he is the only left-behind, he may get so upset and distressed that he is likely to let himself go and make no efforts to solve the problems. While self-confident students will hold right attitude toward score, pressure and evaluation from others, thus they can turn failure into power, when they get high motivation to read, then reading may become an attraction, reading process will be endowed with happiness and enjoyment; Once reading is regarded as a kind of relaxation, feeling of anxiety will disappear. Teacher, as one of key factors in the learning

\section{IMPLICATIONS TO ENGLISH TEACHING}

The present research proves that foreign language reading does provoke anxiety among foreign language learners in college. Given the important functions of reading in college English teaching and learning, it is urgent for English teachers to carry out some investigations in order to know about students' anxiety, it is necessary for teachers to take some appropriate measures to alleviate reading anxiety and enhance the English teaching efficiency.

Secondly, the present research indicates that most students have no confidence in reading English because of rather high anxiety, so it is important for teachers to release anxiety because anxiety seriously affected students' reading performance and reading effects. If students are always in anxious situation, they will suffer from failure of learning. Teachers should be able to diagnose learners' reading anxiety precisely and then help students to cope with the anxiety-provoking situations. If students read in comfortable environment and are encouraged frequently by teachers rather than being criticized, students will become more confident.

Thirdly, teachers should make students be aware that foreign language reading anxiety is Thirdly, teachers should make students be aware that foreign language reading anxiety is natural and common due to the fact that foreign language learning is intrinsic and no one can experience null anxiety, both they themselves and their peers endure 
FLRA, and it is not humiliating to feel anxious in reading. Using this way of encouragement, teachers may cultivate students' confidence in reading. It is obvious that severe FLRA can lower students' self-esteem, inhibit their thoughts, lessen their interests and decrease the degree of reading proficiency. So we should try to provide students with more chances to experience success in reading English, by which their positive self-concepts about reading can be reinforced.

Fourthly, teachers should try their best to develop students into ideal FL readers who can identify the specific factors resulting in their reading anxiety, who can keep a happy and an active psychological and emotional state, all these help greatly to control anxiety. It is necessary for both teachers and students to pay special attention to such affective factors as anxiety, self-esteem, and pay attention to cultivating students' positive attitude toward FLR, encouraging students to exchange their anxious feelings during reading with their peers through some reading activities.

\section{REFERENCES}

[1] Bailey, K.M. (1983). Competitiveness and anxiety in adult second language learning: Looking at and through the diary studies. In H.W. Seliger and M.H. Long(eds.), Classroom oriented research in second language acquisition. Rowley, MA: Newbury House.

[2] B.B. Wolman. (1989). Dictionary of Behavioral Science. New York: Van Nostrand Reinhold co.

[3] Cheng, Y., Horwitz, E.K., \& Schallert, D. (1999). Language anxiety: Differentiating writing and speaking components. Language Learning, 49, 417-446.

[4] Horwitz, E.K. \& Young, D.J. (1991). Language learning Anxiety: From theory and research to classroom implications. Englewood Cliffs, NJ: Prentice Hall.

[5] Krashen, S.D. (1982). Principles and practice in second language acquisition. Oxford: Pergamon.

[6] Krashen, S.D.(1985b). The Input Hypothesis: Issues and implications. New York: Longman.

[7] MacIntyre, P.D. and R.C. Gardner.(1989). Anxiety and second language reading and listening comprehension. Modern Language Journal, 73, 32-40.

[8] Maximo, R. \& Orangel, A.(2003). The stability of general foreign language classroom anxiety across English and French. Model Language Journal 87,365-374.

[9] Scovel, T. (1978). The effects of affect on foreign language learning: A review of the anxiety research. Language learning, 28,129-142.

[10] Spielberger, C.D. (1983). Manual or the State-Trait Anxiety Inventory. Palo Alto, CA: Consulting Psychologists Press.

[11] Williams, K. (1991). Anxiety and foreign language learning. RELC Journal, 22:19-28.

[12] Young, D.J. (1991). Creating a low-anxiety classroom environment: what does the language anxiety research suggest. Modern Language Journal, 75:426-437.

[13] Young, D. J.(1992). Language anxiety form the foreign language specialist's perspective: Interviews with Krashen, Omaggio Hadley, Terrell, and Rardin. Foreign Language Annals, 25,157-172.

Qian Huang was born in hangzhou, China in 1966.She received her M.A. degree in history from Shandong University, China. She is currently an associate professor in foreign language teaching department, Dezhou University, China. Her research interests include linguistics and foreign teacher's education. 